\title{
Chapter 26 \\ Early Maturity in Wheat for Adaptation to High Temperature Stress
}

\author{
Suchismita Mondal, Arun K. Joshi, Julio Huerta-Espino, and Ravi P. Singh
}

\begin{abstract}
High temperatures pose a serious threat to productivity maintenance and enhancement in wheat. A strategy that has come forward in the CIMMYT breeding program is the development of high yielding early maturing lines that are adapted to high temperature stress especially for South Asia. The high temperature stress in South Asia is classified into terminal high temperature stress where the high temperatures stress occurs during grain filling stages, and continual high temperature stress, where high temperature persists across the wheat growing season. The new high yielding, early maturing and heat tolerant CIMMYT wheat lines were evaluated for grain yield and adaptation across diverse locations in South Asia and Mexico. Trials were conducted for three consecutive years 2009-2010, 2010-2011, and 2011-2012. The results suggest that CIMMYT lines with high yields and early maturity, selected under normal and late sown condition in Cd. Obregon, Mexico, have the potential to adapt and outperform normal maturing check varieties under terminal and continual high temperature stress in South Asia. Earliness favored the plants to escape terminal high temperature stress and also promoted an efficient utilization of available resources under continual high temperature stress to achieve higher grain yield. The simultaneous enhancement of grain yield potential and heat stress tolerance of early maturing wheat lines is likely to be beneficial in enhancing productivity under high temperature stress across South Asia.
\end{abstract}

S. Mondal $(\bowtie) \bullet$ R.P. Singh

International Maize and Wheat Improvement Center (CIMMYT),

Int. Apdo. Postal 6-641, Mexico, DF 06600, Mexico

e-mail: s.mondal@cgiar.org

A.K. Joshi

International Maize and Wheat Improvement Center (CIMMYT),

South Asia Office, Kathmandu Office, Kathmandu, Nepal

Department of Genetics and Plant Breeding, Institute of Agricultural Sciences,

Banaras Hindu University, Varanasi 221005, India

J. Huerta-Espino

International Maize and Wheat Improvement Center (CIMMYT),

Int. Apdo. Postal 6-641, Mexico, DF 06600, Mexico

Campo Experimental Valle de Mexico INIFAP,

Apdo. Postal 10, Chapingo, Edo de Mexico 56230, Mexico

(C) The Author(s) 2015

Y. Ogihara et al. (eds.), Advances in Wheat Genetics:

From Genome to Field, DOI 10.1007/978-4-431-55675-6_26 
Keywords Early maturity $\bullet$ Heat stress $\bullet$ Heat tolerance $\bullet$ South Asia $\bullet$ Wheat

\section{Temperature Stress and Wheat Production}

Increasing variation in climate across the globe has become a serious concern to crop production. Wheat, a temperate crop, prefers a cooler climate for growth and reproduction. High temperatures during crop growth and grain filling stages are a major concern to its production. South Asia, comprising of India, Nepal, Pakistan and Bangladesh is one of the major wheat producing and consuming area in the world. This region suffers significant losses each year due to high temperature stress (Kumar et al. 2013). A recent study by World Bank predicts that a $2{ }^{\circ} \mathrm{C}$ rise in world average temperature may lead to extreme heat conditions in South Asia. With estimated losses of 6-20\% per degree rise in temperatures in South Asia, (Mondal et al. 2013; Lobell et al. 2008) high temperatures are a serious threat to wheat production.

The wheat producing areas in South Asia are grouped into mega environments (ME) based on the classification system developed by CIMMYT (Braun et al. 1992). ME1 is defined as the optimally irrigated highly productive environment where wheat grows in cool temperatures but suffers from terminal high temperature stress, such as North Western Gangetic Plain. ME5 is a rainfed, warm regions, where continuous high temperature stress is a major concern and comprises of eastern Gangetic plain, peninsular India, plains of Nepal and Bangladesh. ME1 has a cooler climate during crop growth which gradually increases during reproductive and grain filling stages in March and April. ME5 has warmer temperatures across the crop season. Similar trends are seen for maximum and minimum temperatures for ME1 and ME5 locations in South Asia (Fig. 26.1). Thus it is imperative to develop wheat varieties that are high yielding as well as tolerant to high temperature stress.

\section{Heat Adaption Strategies}

A number of traits have been studied in wheat for adaptation under high temperature stress. One of the strategies being followed in CIMMYT is breeding for early maturing high yielding heat tolerant wheat varieties. Earliness or early maturity is an adaptation strategy where early heading lines complete the initial seed setting and grain filling under favorable temperatures and avoid the late incidence of heat stress. Earliness has been suggested as a good approach for wheat breeding in the eastern Gangetic plains that suffers from high temperature stress during grain filling (Joshi et al. 2007). Tewolde et al. (2006) evaluated a diverse set of US wheat 


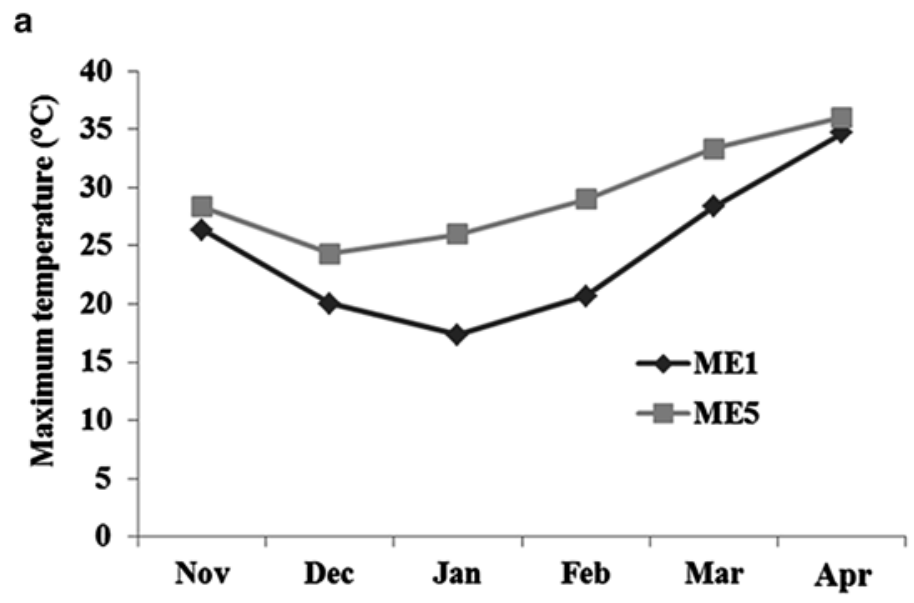

b

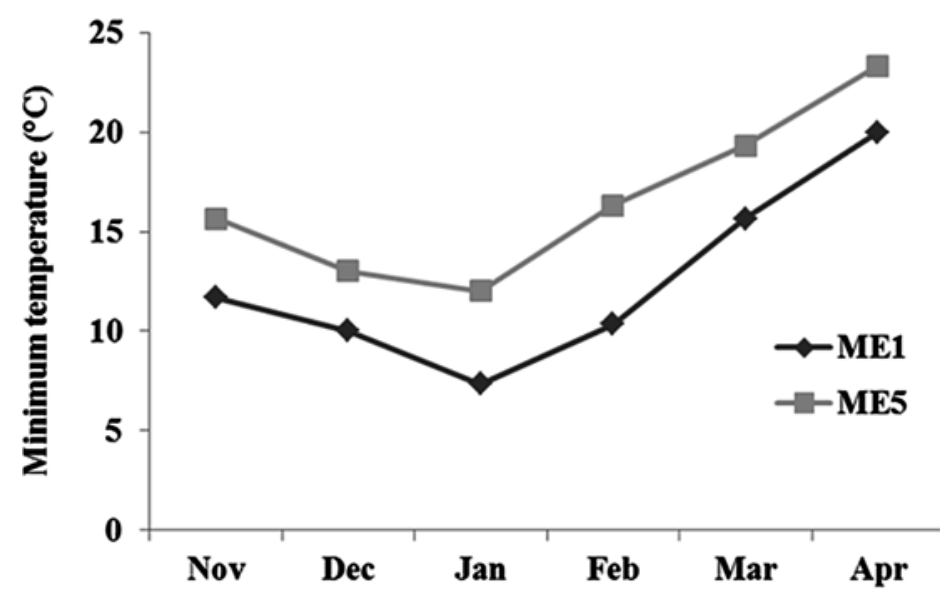

Fig. 26.1 Maximum (a) and minimum (b) temperatures during the wheat crop growing cycle (November, 2012-April, 2013) across ME1 and ME5 locations in South Asia

cultivars for their adaption to high temperature stress and concluded that early maturity was the single effective trait that defined adaptation under post heading high temperature stress. Al-Karaki (2011) observed that the length of pre heading period in durum wheat affects grain yield under heat stress conditions. They reported that the early maturing high yielding durum lines were suitable for the heat stress affected areas in semi-arid environment. Thus the early maturing high yielding CIMMYT wheat lines developed in Mexico were evaluated for grain yield and adaptation to high temperature stress in South Asia. 


\section{Performance of Early Maturing Wheat Lines}

High yielding early maturing wheat lines were developed and tested in CIMMYT research station, Cd. Obregon, Sonora, Mexico. The best performing lines were selected for evaluation in South Asia and Mexico. Each trial had 28 entries, with one CIMMYT check 'Baj' and a local check which was the best locally adapted variety at each location. The trials were grown in 9,13 and 15 locations across South Asia in 2009-2010, 2010-2011 and 2011-2012 respectively. Each year the trials were also planted at $\mathrm{Cd}$. Obregon, Mexico in two environments, normal sowing in November and late sowing in February for heat stress. The locations were grouped in to mega environments, ME1 and ME5.

In $2009-2010,20 \%$ of the lines had grain yield $1-4 \%$ higher $(\mathrm{p}<0.05)$ than the local check across all locations (Fig. 26.2). In the next two cycles (2010-2011 and 2011-2012) nearly $50 \%$ of the lines yielded $1-20 \%$ higher $(\mathrm{p}<0.05)$ than the local checks. A similar trend was seen when compared to the CIMMYT early maturing check line 'Baj'. In 2009-2010 a few lines were performing above 'Baj', but a gradual increase was seen in 2010-2011 and 2011-2012. Thus early lines bred in Mexico were able to outperform the locally adapted checks in South Asia. The performance of the lines in the individual MEs was also interesting. The mean grain yield of the trial had significant reduction in the warm ME5 compared to cooler ME1. When the entries that performed above local check in both MEs in each year were grouped together, it was observed that each year these entries had around 5-10\% yield advantage ( $\mathrm{p}<0.05)$ over the local checks in each ME (Fig. 26.3). Thus the early maturing high yielding lines were able to adapt under both terminal and continual high temperature stresses.

High temperatures affect both grain filling duration and grain filling rate. Studies have reported an increase in grain filling rate and reduction in grain filling duration due to high temperatures (Farooq et al. 2011). But the increase in grain filling rate has been reported to not compensate for the shorter grain filling duration (Wardlaw et al. 1980; Stone et al. 1995). The results from this study show otherwise. The early maturing short duration wheat lines were able to outperform the best locally adapted varieties. A comparison of grain accumulation rate based on grain filling duration of the five top high yielding stable lines in each year with the local checks showed that the early maturing lines had higher grain accumulation rates as well as higher grain yields (Fig. 26.4).

\section{Conclusions}

With high temperature becoming a major issue in wheat producing areas, there is an enhanced focus on developing heat tolerant high yielding wheat varieties. The results show that simultaneous enhancement of yield potential and heat tolerance is possible and that the CIMMYT strategy to develop high yielding early maturing wheat lines is promising for South Asia. The early maturing lines were able to 
a

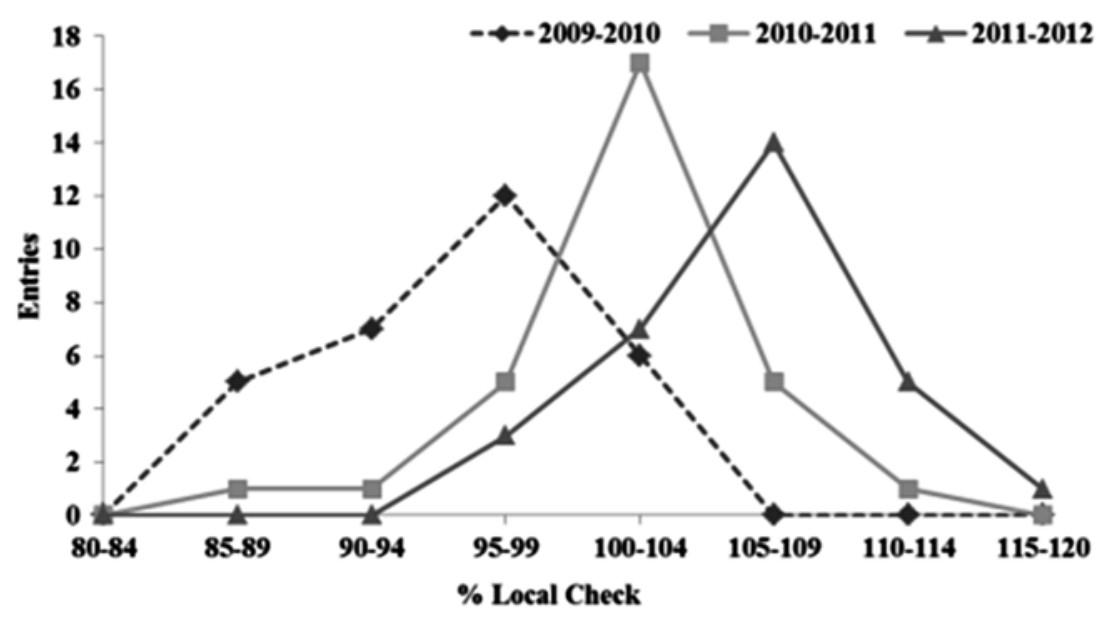

b

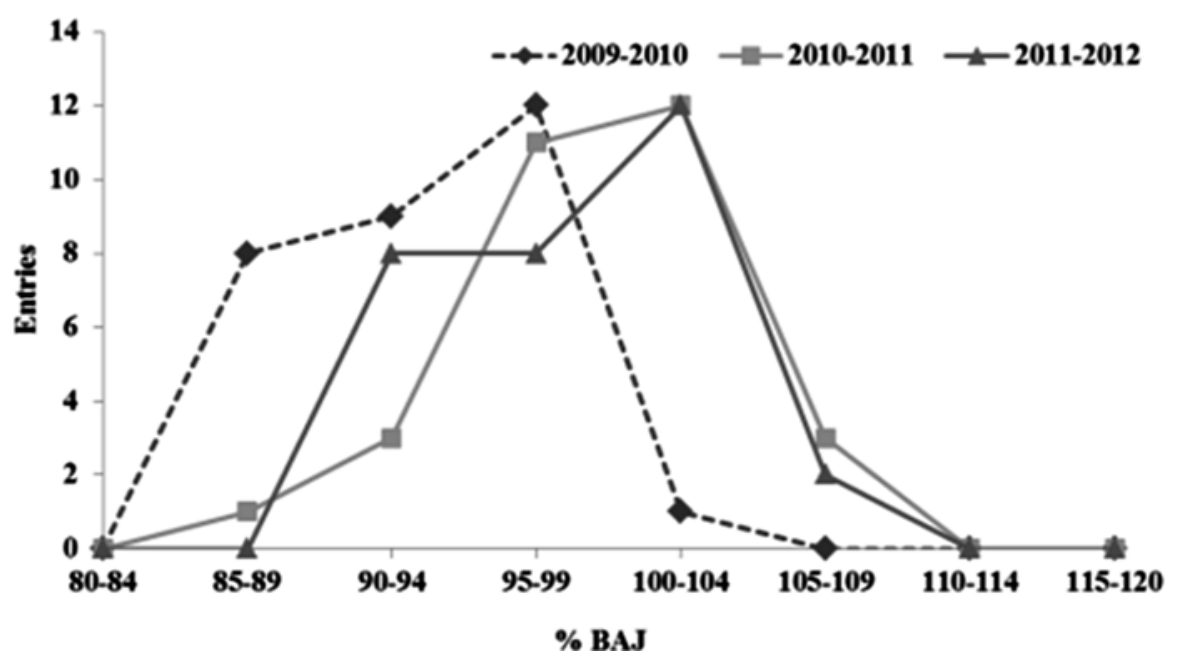

Fig. 26.2 Mean grain yield of the 30 lines across South Asia in 2009-2010, 2010-2011 and 2011-2012. Grain yield is expressed as \% above (a) local check and (b) CIMMYT check line BAJ

outperform the locally adapted high yielding lines under both terminal and continual high temperature stress. Thus early maturity while maintaining yield superiority is beneficial for South Asia in adapting to high temperature stress and enhancing productivity. The identified heat tolerant, high yielding and early maturing Lines are available for the national wheat improvement programs in South Asia for testing and further development of superior heat tolerant wheat varieties. 


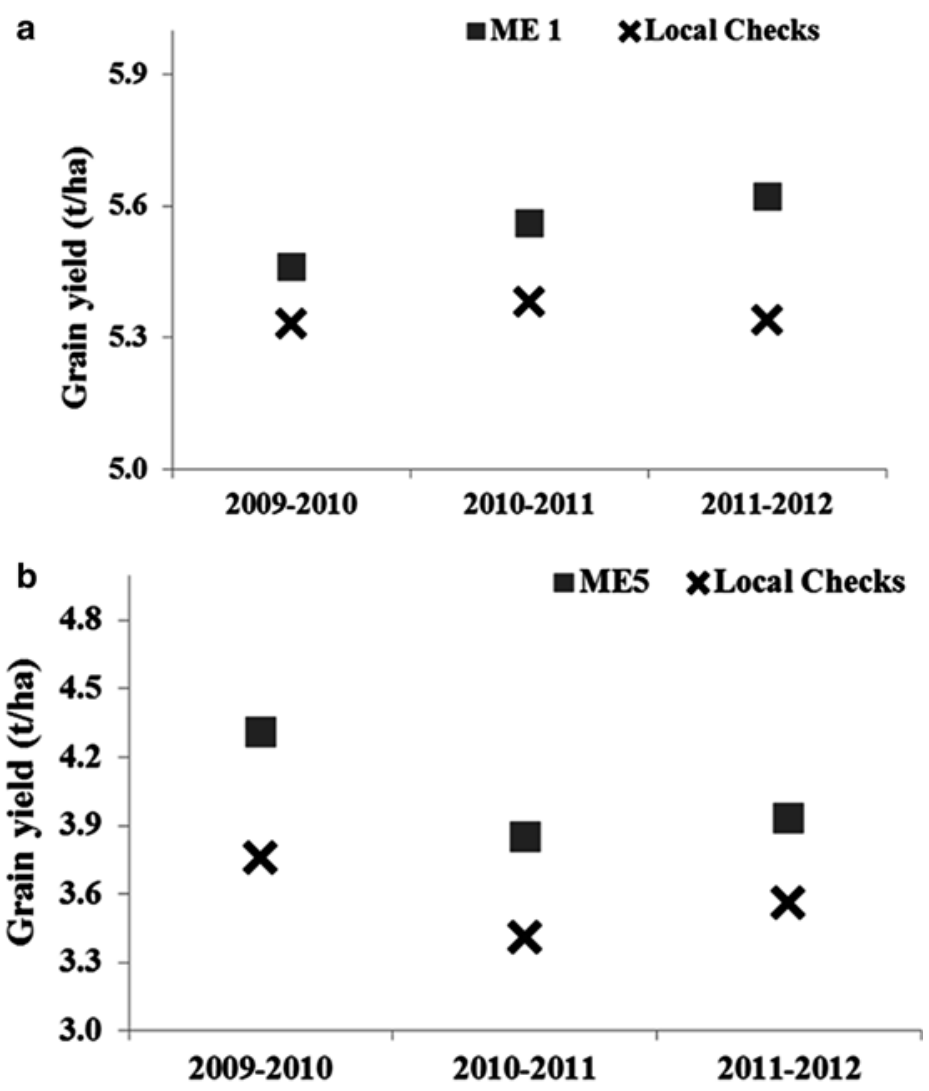

Fig. 26.3 Grain yield of the top five lines and local checks in (a) ME1 and (b) ME5 of South Asia in 2009-2010, 2010-2011 and 2011-2012

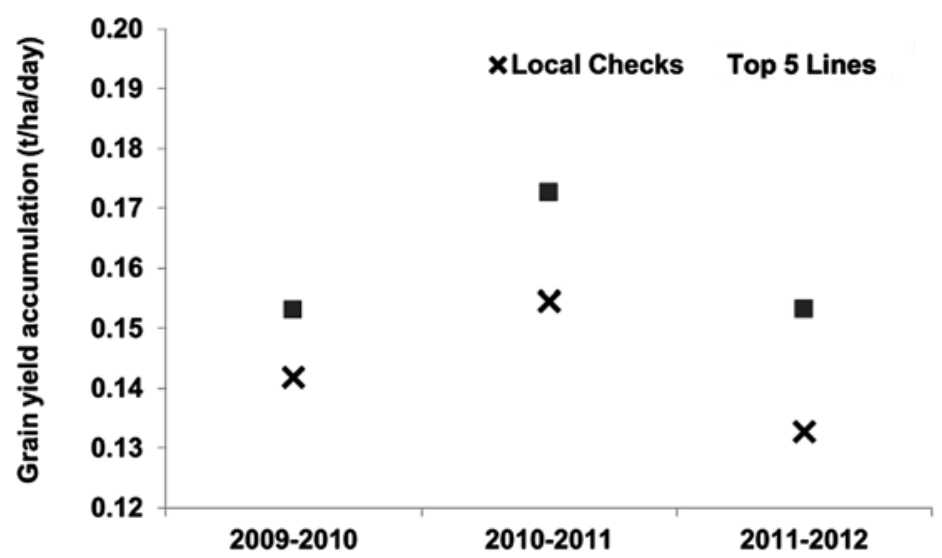

Fig. 26.4 Grain yield accumulation rate ( $t /$ ha/day) of the top five lines and local checks in South Asia in years 2009-2010, 2010-2011 and 2011-2012 
Acknowledgments We would like to thank all our co-operators and National Agricultural Research Station partners in India, Bangladesh, Nepal and Pakistan for conducting trials at the respective locations and donor organizations Bill \& Melinda Gates Foundation and USAID for providing financial support through the CSISA project.

Open Access This chapter is distributed under the terms of the Creative Commons Attribution Noncommercial License, which permits any noncommercial use, distribution, and reproduction in any medium, provided the original author(s) and source are credited.

\section{References}

Al-Karaki GN (2011) Phenological development- yield relationships in durum wheat cultivars under late season high -temperature stress in a semiarid environment. ISRN Agron 2012, 456856. doi:10.5402/2012/456856, 7 pages

Braun HJ, Pfeiffer WH, Pollmer WG (1992) Environments for selecting widely adapted spring wheat. Crop Sci 32:1420-1427

Farooq M, Bramley H, Palta JA, Sidique KHM (2011) Heat stress in wheat during reproductive and grain filling phases. Crit Rev Plant Sci 30:491-507

Joshi AK, Mishra B, Chatrath R et al (2007) Wheat improvement in India: present status, emerging challenges and future prospects. Euphytica 157:431-446

Kumar S, Kumari P, Kumar U et al (2013) Molecular approaches for designing heat tolerant wheat. J Plant Biochem Biotechnol. doi:10.1007/s13562-013-0229-3

Lobell DB, Burke MB, Tebaldi C et al (2008) Prioritizing climate change adaptation needs for food security in 2030. Science 319:607-610

Mondal S, Singh RP, Crossa J et al (2013) Earliness in wheat: a key to adaptation under terminal and continual high temperature stress in South Asia. Field Crop Res 151:19-26

Stone PJ, Savin R, Wardlaw IF, Nicolas ME (1995) The influence of recovery temperature on the effects of brief heat shock on wheat. I. Grain growth. Aust J Plant Physiol 22:945-954

Tewold H, Fernandez CJ, Erickson CA (2006) Wheat cultivars adapted to post-heading high temperature stress. J Agric Crop Sci 192:111-120

Wardlaw IF, Sofield I, Cartwright PM (1980) Factors limiting the rate of dry matter accumulation in grain of wheat grown in high temperature. Aust J Plant Physiol 7:387-400 